
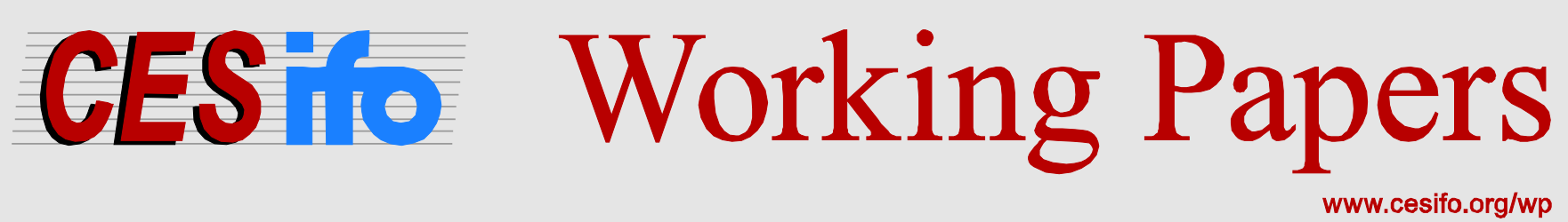

\title{
Employer-Paid Parking, Mode Choice, and Suburbanization
}

\author{
Jan K. Brueckner \\ Sofia F. Franco
}

\begin{abstract}
CESIFO WORKING PAPER NO. 6298
CATEGORY 9: RESOURCE AND ENVIRONMENT ECONOMICS

JANUARY 2017
\end{abstract}

An electronic version of the paper may be downloaded

- from the SSRN website:

- from the RePEc website:

- from the CESifo website:

WWW.SSRN.com

Www.RePEc.org

www.CESifo-group.org/wp 


\title{
Employer-Paid Parking, Mode Choice, and Suburbanization
}

\begin{abstract}
This paper constructs a theoretical model that facilitates analysis of the effects of employer-paid parking on mode choice, road investment and suburbanization. The model simplifies urban space by dividing it into two zones (islands), center and suburbs, which are connected by a congested road and a public-transit line. Each road commuter requires an allotment of CBD land for parking, and because the central zone's area is fixed, parking land reduces the amount available for central residences and CBD production. The model characterizes optimal resource allocation from the perspective of a social planner. The planning solution can be decentralized, which requires employee- rather than employer-paid parking, congestion tolls, and a tax (subsidy) to offset the road capacity deficit (surplus). The analysis then considers the effect of switching to employer-paid parking, with the burden of parking costs shifting from road users to employers, thus reducing the wage for all workers. This switch inefficiently increases road usage and capacity investment, while spurring an inefficient increase in suburbanization.
\end{abstract}

JEL-Codes: R400.

Keywords: employer-paid parking, mode choice, suburbanization.

Jan K. Brueckner

Department of Economics

University of California, Irvine

3151 Social Science Plaza

USA - Irvine, CA 92697

jkbrueck@uci.edu
Sofia F. Franco

Nova School of Business and Economics

Campus de Campolide P-1099-032

Portugal / Lisboa

sfranco@novasbe.pt

December 2016 


\title{
Employer-Paid Parking, Mode Choice, and Suburbanization
}

by

\author{
Jan K. Brueckner and Sofia F. Franco*
}

\section{Introduction}

According to US Census data, 86 percent of all commuters drove to work in 2013 (McKenzie 2015). In addition to creating unwelcome road congestion, this massive automobile commute flow affects land-use in the CBD, with employee parking in the employment centers of US cities consuming substantial amounts of land and other resources. Even though underground parking can limit the loss of land, parking in some CBDs covers more than 20 percent of the total land area. For example, in downtown Los Angeles, CA nearly $24 \%$ of land is allocated to industrial and commercial surface parking lots. ${ }^{1}$ This loss of productive space hurts the city, reducing urban vitality and competitiveness by shifting economic activity away from the CBD. ${ }^{2}$ By contrast, public-transit usage does not create the same land demands as parking. Bus users require no land beyond the city streets on which buses travel, and while commuter rail users require a train station or subway stop, these facilities can be fairly compact and are often underground.

Although a shift toward public transit would thus reduce parking's pressure on available CBD land, the choice between automobile and transit commuting is subject to a major distortion caused by the way parking is provided to workers. In particular, in attempting to attract and retain the best employees, nearly three-fourth of all firms in the U.S. provide free parking for their workers, offering an estimated 85 million free commuter parking spaces with a net worth of nearly $\$ 31.5$ billion (EPA 2005). ${ }^{3}$ Since the practice is more common in large firms, 95 percent of all commuters who drive to work receive free parking. Even in the CBDs of large cities like New York and Los Angeles, where land is most scarce, over 50 percent of automobile commuters receive free parking paid for by their employer (Willson and Shoup 1990, Schaller Consulting 2007). 
When parking is provided by employers, this benefit is viewed as free by employees, even though its cost is borne, almost invisibly, through lower wages for all workers. With no explicit parking cost to bear, workers misperceive the cost of automobile commuting relative to the cost of public transit, producing effects that extend far beyond the confines of the individual firm. Free parking inefficiently discourages transit usage, reduces land availability in the city center, and creates road congestion and air pollution (especially since the vast majority of auto commuters are solo drivers). ${ }^{4}$

As argued by Shoup $(1997,2005)$ and others, this distortion would be eliminated if employers charged workers for the cost of the parking they provide. With employers freed from the burden of parking costs, wages would rise. But the main effect would be to raise perceived auto commuting costs relative to the cost of public transit, encouraging some workers to switch to the transit mode. Therefore, charging employees for parking or letting them cash out their free parking space would lead to more efficient commuting choices.

The purpose of this paper is to construct a model that facilitates analysis of the effects of employer-paid parking on mode choice, road investment, and suburbanization. Following Brueckner and Helsley (2011), the model simplifies urban space by dividing it into two zones (islands), center and suburbs, which are connected by a congested road and a public-transit line. Each road commuter requires an allotment of CBD land for parking, and because the central zone's area is fixed, parking land reduces the amount available for central residences and CBD production. In addition, each road user requires a fixed amount of parking land at their suburban residence. The model characterizes optimal resource allocation from the perspective of a social planner.

The planning solution can be decentralized, which requires employee- rather than employerpaid parking, congestion tolls, and a tax (subsidy) to offset the road capacity deficit (surplus) (the transit fare exactly covers capacity cost given the assumption of constant returns). The analysis then considers the effect of a switch to employer-paid parking, with the burden of parking costs shifting from auto commuters to employers, thus reducing the wage for all workers. The analysis shows that this switch increases road usage and road capacity, while reducing the center's residential land area. The result is greater suburbanization of the population along 
with an overall increase in the suburban commute flow to the CBD. Since all these changes are welfare reducing, the paper thus shows that employer-paid parking leads to inefficiently high road usage and capacity investment along with an excessive degree of suburbanization.

Since these results are derived under the assumption of quasi-linear preferences, the wage reduction's income effect on land consumption is absent, potentially masking important impacts on urban structure. To provide an analysis that captures income effects, the paper also carries out a numerical simulation with Cobb-Douglas preferences, which mainly replicates the patterns seen in the analytical results.

An empirical literature has emerged showing that employer-paid parking encourages automobile commuting (usually in solo fashion) over other modes. The literature contains case studies showing how the employee modal split differs across firms with and without employerpaid parking, as well as before-and-after studies showing how the modal split responds to cessation of this parking policy (see the survey by Willson and Shoup 1990 and Shoup 2005). While public transit is one of the chosen modes in these studies, another is carpooling, which employees adopt in response to higher parking costs. For reasons of analytical tractability, this mode is absent from the current model. The literature also explores the effects of cash-out policies, where employees can either take a free parking space or a wage supplement equal to the parking cost (see Shoup 1997).

This empirical focus on employer-paid parking has not been matched on the theoretical side, with only a few analytical studies devoted to exploring the effects of employer-paid parking on commuting patterns and urban structure. ${ }^{5}$ Borck and Wrede (2008) provide a foundation for such work by studying the distributional effects of commuting subsidies among city residents and absentee landowners in a monocentric city with two transport modes, two income groups, and fixed housing consumption. ${ }^{6}$ Unpublished work by Franco (2014) finds results similar to those in Borck and Wrede (2008), although the focus of her study is on the spatial effects of employer-paid parking modeled as a subsidy for auto users. As in Borck and Wrede (2008), her setup is a closed monocentric model with two transport modes, although it assumes homogenous incomes while allowing for endogenous housing consumption. With suburban (central) residents commuting by auto (public transit), the study shows that a higher 
auto subsidy leads to a shift toward auto commuting at the expense of transit use and greater suburbanization of the population, as in the present paper (but without the current effects on the wage and business land use). ${ }^{7}$

Voith (1998) analyzes the effect of a parking tax used to subsidize transit commuting on total CBD employment, using a model that shares some of the present framework's features. The city in Voith's model is open, nonspatial, and includes agglomeration economies in the CBD, but it has an auto/transit mode choice that resembles the present one, with all commuters indifferent between the modes in equilibrium. The paper briefly considers an extension where parking and CBD production compete for land, as in the present model, but the effects of the parking tax are generally ambiguous. Finally, employer-paid parking appears obliquely in De Borger and Wuyts' (2009) study of the gains from recycling congestion-toll revenue. They show that its presence raises the gain from revenue recycling through higher public-transit subsidies relative to the gain from reducing labor taxes.

The plan of the paper is as follows. Section 2 develops the model, while section 3 uses it to analyze the effect of employer-paid parking. Section 4 presents the numerical example. Section 5 discusses tax incentives for adoption of employer-paid parking, arguing that the seemingly innocuous nontaxability of the parking fringe benefit in fact encourages the major urban distortions detailed in the analysis. Section 6 presents conclusions.

\section{Model}

The city has two islands, with the central island (denoted $c$ ) containing residences, land used for worker parking, and land used in production (see Figure 1). The total central land area is normalized to 1 . Commuting cost within both zones is zero, with residents of the central island walking to work. Access to the center from the suburban island (denoted $s$ ) comes from a road (mode 1) or public transit (mode 2), both of which use bridges. In contrast to parking, public transit requires no central land. The road capacity is $k_{1}$ (which costs $\gamma_{1}$ per unit), and the cost of using the road, which includes time and vehicle costs, is $t\left(n_{s 1}, k_{1}\right)$, where $n_{s 1}$ is the number of suburban residents using it ( $t^{\prime}$ s derivatives satisfy $t^{n}>0, t^{k}<0, t^{n n}, t^{k k}>0$ ). The transit user-cost curve is horizontal at height $\alpha$, which gives the fixed time cost of public- 
transit use, as long as $n_{s 2}$ is less than capacity, denoted $k_{2}$. The user-cost curve becomes vertical when $n_{s 2}$ reaches $k_{2}$, indicating unbounded costs from exceeding capacity, or "infinite" public-transit crowding. ${ }^{8}$ As a result, capacity (which costs $\gamma_{2}$ per unit) will always be set equal to $n_{s 2}$. With constant costs, provision of public-transit capacity thus exhibits constant rather than increasing returns, an assumption that helps to make the analysis tractable (it may be realistic for buses, but not for rail transit). ${ }^{9}$

It should be noted that this framework assumes that commuters do not have an innate preference for driving or transit use, which would introduce heterogeneity into the model with no effect on the main results. Without heterogeneity, commuters in a decentralized setting would choose the cheapest mode, a rule that the planner would also follow. Finally, workers walking to work or commuting by public transit are assumed not to own a car. ${ }^{10}$

Production in the CBD depends on land and labor inputs, with the CRS production function given by $F(\ell, L)$, where $\ell$ is the land input and $L$ is the number of workers, equal to the city population, which is fixed at unity. Output can then be written as $L F(\ell / L, 1)=$ $L f(\ell / L)=f(\ell)$, setting $L=1$ and letting $f$ denote the intensive production function $\left(f^{\prime}\right.$ is thus the marginal product of land, and $f^{\prime \prime}<0$ holds). The land input satisfies $\ell=1-\beta P-n_{c} q_{c}$, where $P$ is the number of parking spaces, $\beta$ is land area per space, and $n_{c}$ and $q_{c}$ are the number of central residents and their land consumption. The suburban values are $n_{s}$ and $q_{s}$, and in addition, $\beta P$ worth of suburban land is needed for residential parking. Let utility be quasi-linear, being given by $e_{i}+v\left(q_{i}\right)$, for $i=c, s$, where $e_{i}$ is nonland consumption and $v^{\prime}>0, v^{\prime \prime}<0$ hold.

\subsection{The social planner's problem}

The planner's problem is to maximize the city's uniform utility level $u$ subject to various constraints. Letting $r_{a}$ denote the exogenous opportunity cost of land (agricultural rent), the Lagrangean expression for the planning problem can be written as follows: 


$$
\begin{aligned}
u & +\lambda\left[1-\left(n_{c}+n_{s}\right)\right] \\
& +\theta_{c}\left(e_{c}+v\left(q_{c}\right)-u\right)+\theta_{s}\left(e_{s}+v\left(q_{s}\right)-u\right) \\
& +\delta\left\{f\left(1-\beta P-n_{c} q_{c}\right)-\left[n_{s} e_{s}+n_{c} e_{c}+r_{a}\left(1+n_{s} q_{s}+\beta P\right)+\gamma_{1} k_{1}+\gamma_{2} n_{s 2}+n_{s 1} t\left(n_{s 1}, k_{1}\right)+n_{s 2} \alpha\right]\right\} \\
& +\phi\left(P-n_{s 1}\right) \\
& +\mu\left(n_{s 1}+n_{s 2}-n_{s}\right) .
\end{aligned}
$$

The first constraint (with multiplier $\lambda$ ) is the overall population constraint, and the two constraints on the second line of (1) are the utility constraints. The next constraint (with multiplier $\delta$ ) is the resource constraint. The first term involving $f$ is the city's output. This output must cover non-land consumption (the next two terms), land costs (inclusive of suburban parking land), the costs of transport capacity (the next two terms; recall $k_{2}=n_{s 2}$ ), and commuting costs (the last two terms). The last two constraints say that the number of parking spaces equals $n_{s 1}$ and that users on the two modes add up to $n_{s}$, the suburban population. ${ }^{11}$

The first-order conditions for the planning problem (which are shown in the appendix) can be manipulated to yield a set of necessary conditions for an optimum. The first two of these conditions $\operatorname{are}^{12}$

$$
\begin{aligned}
& v^{\prime}\left(q_{c}\right)=f^{\prime} \\
& v^{\prime}\left(q_{s}\right)=r_{a} .
\end{aligned}
$$

Note that since $f^{\prime}$, the marginal product of land in CBD production, will equal land rent in the central zone in a decentralized equilibrium, (2) and (3) equate marginal utilities to decentralized land rents.

The next condition is ${ }^{13}$

$$
t+n_{s 1} t^{n}+\beta\left(f^{\prime}+r_{a}\right)=\alpha+\gamma_{2},
$$


which says that the social cost of an extra user should be the same on the two modes, holding $k_{1}$ fixed. The social cost of an extra road user includes $t$ along with congestion cost $n_{s 1} t^{n}$ and the cost $\beta\left(f^{\prime}+r_{a}\right)$ of parking land at both ends of the commute trip (recall that $f^{\prime}$ represents central land rent), while the social cost of an extra transit user is the commuting cost incurred $(\alpha)$ plus the additional capacity cost $\left(\gamma_{2}\right)$. Since the LHS of (4) is increasing in $n_{s 1}$, the equation yields a unique solution for $n_{s 1}$ conditional on $k_{1}$. For $n_{s 1}$ values below this solution, the road usage is less costly than transit usage, making an increase in $n_{s 1}$ optimal, while a decrease is optimal for $n_{s 1}$ values above the solution.

The condition for optimal road capacity is

$$
-n_{s 1} t^{k}=\gamma_{1}
$$

(recall $t^{k}<0$ ). This condition says that the marginal benefit from a marginal capacity expansion should equal the cost. The next condition is ${ }^{14}$

$$
e_{c}+f^{\prime} q_{c}=e_{s}+r_{a} q_{s}+\alpha+\gamma_{2} .
$$

This condition characterizes the division of the population between the central and suburban zones, which is optimal when the resource consumption of an extra person is equal in the two zones. Although the public-transit cost appears on the RHS of (6), the fact that this cost equals the road cost via (4) means that (6) pertains to users of both modes.

The $e_{i}$ variables in (6) can be eliminated using the utility constraints, with $e_{i}=u-v\left(q_{i}\right)$, $i=c, s$, substituted on the two sides of (6). After cancellation of $u$ and substitution of $v^{\prime}\left(q_{c}\right)$ and $v^{\prime}\left(q_{s}\right)$ in place of $f^{\prime}$ and $r_{a}$, respectively, (6) becomes

$$
q_{c} v^{\prime}\left(q_{c}\right)-v\left(q_{c}\right)=q_{s} v^{\prime}\left(q_{s}\right)-v\left(q_{s}\right)+\alpha+\gamma_{2} .
$$

Since $q_{s}$ is independently determined by equating $v^{\prime}\left(q_{s}\right)$ to the exogenous $r_{a}$, the RHS of (7) can be treated as fixed. As a result, (7) determines $q_{c}$. With $q_{c}$ given, (2), (4) and 
(5) then constitute three equations to determine $n_{s 1}, k_{1}$ and $n_{c}$ (recall that $f$ 's argument is $\left.1-\beta n_{s 1}-n_{c} q_{c}\right)$. The remaining unknowns, $u, n_{s 2}, n_{s}, e_{c}, e_{s}$, and $P$, are then determined via the constraints in (1).

Note that since $q v^{\prime}(q)-v(q)$ is decreasing in $q$ (with derivative $q v^{\prime \prime}<0$ ), $q_{c}<q_{s}$ must hold for (7) to be satisfied, so that land consumption is smaller in the central zone than in the suburbs, as expected. In addition, (2) and (3) then imply that $f^{\prime}>r_{a}$ must hold, so that the center commands the expected rent premium.

\subsection{Decentralizing the planning solution}

The planning solution can be decentralized by setting road capacity optimally (satisfying (5)), adjusting transit capacity to equal ridership, imposing a road congestion toll equal to $n_{s 1} t^{n}$, setting the transit fare equal to $\gamma_{2}$, and requiring road users to acquire their own parking land in the center as well as in the suburbs. With these charges, the equilibrium condition determining the split between transit and road usage is the same as the optimality condition (4). ${ }^{15}$ In addition, the optimality conditions (2) and (3) are satisfied under decentralization, condition (6) holds given the common incomes of central and suburban residents, and (7) (derived from (6) by imposing the equal-utility restriction) also holds since equal utilities is a condition of equilibrium.

Although transit capacity cost is exactly covered by fares, the relation between toll revenue and road capacity cost depends on the nature of the $t$ function, with any shortfall or excess of revenue covered by a lump-sum tax or transfer. With land rent in the central zone equal to $f^{\prime}$, the wage earned by workers equals $f-\ell f^{\prime}=f-\left(1-\beta n_{s 1}-n_{c} q_{c}\right) f^{\prime}$, a residual equal to output minus land cost, on a per-worker basis. In addition, the decentralized city must have internal land ownership (being fully closed), with differential rent (land rent in excess of $r_{a}$ ) accruing to residents as income on an equal per-capita basis. It should be noted that, although workers are viewed as renting their parking land directly, parking could be provided by competitive firms that rent land and resell it as parking spaces (while incurring no capital cost).

It is helpful to consider the aggregate budget constraint under decentralization. The income side of the budget constraint equals total wages plus differential land rent minus a tax to pay for the road capacity deficit (the tax is negative in the case of a surplus). Recalling that the 
labor force size equals 1 , total income is then

$$
f-\left(1-\beta n_{s 1}-n_{c} q_{c}\right) f^{\prime}+f^{\prime}-r_{a}-\left(\gamma_{1} k_{1}-n_{s 1}^{2} t^{n}\right)
$$

where $f^{\prime}-r_{a}$ is differential land rent (recall that the central land area equals 1 ) and $n_{s 1}^{2} t^{n}$ is toll revenue. Note that since profit of CBD producers is zero, there is no corresponding income term.

Total expenditures are given by

$$
r_{a}\left(q_{s} n_{s}+\beta n_{s 1}\right)+f^{\prime} n_{c} q_{c}+n_{s 1} \beta f^{\prime}+n_{s 1}\left(t+n_{s 1} t^{n}\right)+\left(\alpha+\gamma_{2}\right) n_{s 2}+n_{c} e_{c}+n_{s} e_{s},
$$

where the second and third terms are rent outlays and total parking costs in the center, and where the fourth term includes congestion tolls. Setting income equal to expenditures, and rearranging, it is easily seen that the resulting equality reduces to the aggregate resource constraint from (1).

To write the individual budget constraints, note that since the population size $L$ equals 1, (8) also gives individual income. The expenditure sides of the individual constraints are $e_{c}+f^{\prime} q_{c}$ for central residents, $e_{s}+r_{a} q_{s}+\alpha+\gamma_{2}$ for suburban transit users, and $e_{s}+r_{a}\left(q_{s}+\right.$ $\beta)+t+n_{s 1} t^{n}+\beta f^{\prime}$ for suburban road users.

\section{Analysis}

\subsection{The effect of a switch to employer-paid parking with $k_{1}$ fixed}

The model can be used to analyze how a city with employer-paid parking differs from one with employee-paid parking. To address this question, start with the decentralized planning solution, and suppose that employers now provide parking without charge to workers, renting the required land in place of the workers. Note, however, that auto commuters still need to pay for their residential parking in the suburbs. One result will be a reduction in the wage, with the parking cost spread across all workers, road plus transit users as well as central residents. This change can be seen in the aggregate budget constraint based on (8) and (9). The aggregate 
parking-cost term $n_{s 1} \beta f^{\prime}$ on the RHS of the expenditure expression (9) is set to zero, with this term instead subtracted from the wage in the income expression (8) (note that with $L=1$, both total and individual wages decline by $\left.n_{s 1} \beta f^{\prime}\right)$. It is crucial to recognize that the wage is not adjusted on an individual basis depending on whether or not a worker uses employer-paid parking; all wages decline to cover its costs. In addition, the wage is viewed as parametric by workers, so that in making his mode choice, the worker does not recognize that a decision to drive to work would reduce total (and individual) wages by the extra parking cost $\beta f^{\prime}$ he would generate.

Suppose also that road capacity is held fixed at the first-best level in the switch to employerpaid parking, but that transit capacity is adjusted in step with ridership. In addition, suppose that a road congestion toll continues to be levied, with its magnitude adjusting to changes in traffic.

Since the switch eliminates $\beta f^{\prime}$ from the mode-choice condition (4), road usage becomes cheaper than public transit, encouraging some commuters to shift to the road. With $n_{s 1}$ thus increasing, $t+n_{s 1} t^{n}$ increases as well, rising until it equals $\alpha+\gamma_{2}-\beta r_{a}$. As a result, an increase in road congestion from the traffic shift completely eliminates the auto commuter's cost savings from employer-paid parking. With $n_{s 1}$ larger, more central parking land is needed, exerting downward pressure on the land available for production and residences in the center. However, since the shift to employer-paid parking has no effect on $q_{c}$, which is still determined by $(7)$, it follows from (2) that $f^{\prime}$ (and thus its argument $1-\beta n_{s 1}-n_{c} q_{c}$ ) must also be unchanged. The upshot is that the increase in required parking land must be exactly offset by a decrease in residential land, which occurs via a decline in $n_{c}$. This decline has no effect on $n_{s 1}$, which is determined solely by the new (4). As a result, the new suburban commuters created by the lower $n_{c}$ all use public transit. Whether this traffic rebound is sufficient to offset the initial decline in transit users is unclear. Overall, therefore, the switch to employer-paid parking leads to increased road usage and greater decentralization, with population shifting toward the suburbs. Even though the change in transit usage is ambiguous, greater suburbanization implies that the switch leads to a larger overall commute flow to the CBD.

It is easy to see that the previous conclusions hold in a more realistic situation where $k$ is 
fixed at some nonoptimal level, and they also hold for arbitrary $k$ in the absence of congestion tolls. In both cases, $n_{s 1}$ must rise to equate road and transit costs, with $n_{c}$ then falling. Another point to note is that, because of quasi-linear preferences, the income effect on land consumption from the lower wage is absent from the previous results, with only the $e_{i}$ 's being affected. Thus, one possible channel by which the switch can affect suburbanization and urban structure is neutralized.

\subsection{The effect of a switch to employer-paid parking with $k_{1}$ adjusted}

These results can be derived formally by multiplying $\beta f^{\prime}$ in (4) by the factor $\mu$, which equals zero with employer-paid parking. This change also appears in the aggregate decentralized budget constraint, with $n_{s 1} \beta f^{\prime}$ in (9) multiplied by $\mu$ and $(1-\mu) n_{s 1} \beta f^{\prime}$ subtracted from the income expression (8). Comparative-static analysis of $\mu$ 's effects is then carried out using (2) and (4), with a reduction of $\mu$ from 1 to 0 corresponding to the switch to employer-paid parking ( $\mu$ is thus the employee's parking cost share).

While this exercise is straightforward and confirms the logic from above, a less straightforward exercise analyzes the shift to employer-paid parking when road capacity $k_{1}$ adjusts according to the first-best optimality condition (5). As seen below, satisfaction of the firstbest capacity condition may not be desirable under the distortion of employer-paid parking, but real world decisions would be likely to follow such a rule. The required analysis makes use of the three-equation system consisting of (2), (4), and (5), and the same setup can also be used to derive the effect of the parking efficiency parameter $\beta$ on the first-best allocation, with $\mu$ set equal to 1.

Letting $\bar{q}_{c}$ denote the fixed value of $q_{c}$ from (7), totally differentiating (2), (4) and (5) yields

$$
\begin{gathered}
\left(\begin{array}{ccc}
\beta f^{\prime \prime} & 0 & \bar{q}_{c} f^{\prime \prime} \\
2 t^{n}+n_{s 1} t^{n n}-\mu \beta^{2} f^{\prime \prime} & t^{k}+n_{s 1} t^{k n} & -\mu \bar{q}_{c} \beta f^{\prime \prime} \\
t^{k}+n_{s 1} t^{k n} & n_{s 1} t^{k k} & 0
\end{array}\right)\left(\begin{array}{c}
d n_{s 1} \\
d k_{1} \\
d n_{c}
\end{array}\right) \\
=\left(\begin{array}{c}
0 \\
-\beta f^{\prime} \\
0
\end{array}\right) d \mu+\left(\begin{array}{c}
-n_{s 1} f^{\prime \prime} \\
-\left(f^{\prime}+r_{a}-\beta n_{s 1} f^{\prime \prime}\right) \\
0
\end{array}\right) d \beta .
\end{gathered}
$$


Let $M$ denote the $2 \times 2$ matrix in the bottom right corner of the $3 \times 3$ matrix in the first line of (10), once the term $\mu \beta^{2} f^{\prime \prime}$ has been suppressed. The resulting matrix is the Hessian matrix of $n_{s 1} t\left(n_{s 1}, k_{1}\right)$, which is positive definite under the assumption that this expression, equal to total road commuting cost, is strictly convex in $n_{s 1}$ and $k_{1} \cdot{ }^{16}$ As result, the determinant of $M$, denoted $H$, must be positive along with the matrix's diagonal elements (the latter requirement follows from $t^{n n}, t^{k k}>0$ ). It can be shown that, after simplification, the determinant of the 3 $\times 3$ matrix then reduces to $D \equiv \bar{q}_{c} f^{\prime \prime} H<0$.

Using Cramer's rule (with $d \beta=0$ ) and letting $x=-\beta f^{\prime} f^{\prime \prime}>0$ and $z=x n_{s 1} t^{k k}>0$, the comparative-static derivatives with respect to $\mu$ are

$$
\frac{\partial n_{s 1}}{\partial \mu}=\frac{\bar{q}_{c} z}{D}<0, \quad \frac{\partial n_{c}}{\partial \mu}=-\frac{\beta z}{D}>0, \quad \frac{\partial k_{1}}{\partial \mu}=-\frac{\bar{q}_{c} x\left(t^{k}+n_{s 1} t^{k n}\right)}{D}>(<) 0 .
$$

Therefore, when $\mu$ decreases, moving toward the zero value corresponding to employer-paid parking, $n_{s 1}$ increases and $n_{c}$ decreases, as in the simpler fixed- $k_{1}$ case above. The adjustment in $k_{1}$ depends on the sign of $-\left(t^{k}+n_{s 1} t^{k n}\right)$, which is the derivative of the marginal benefit of capacity $\left(-n_{s 1} t^{k}\right)$ with respect to $n_{s 1}$. If this expression is positive, naturally indicating that extra capacity helps more when $n_{s 1}$ is high and the road is heavily congested, then $t^{k}+n_{s 1} t^{k n}<0$ holds and $\partial k_{1} / \partial \mu$ is negative like $\partial n_{s 1} / \partial \mu$, indicating that both $n_{s 1}$ and $k_{1}$ increase in the switch to employer-paid parking. ${ }^{17}$

Note also that since

$$
\frac{\partial n_{s 2}}{\partial \mu}=\frac{\partial n_{s}}{\partial \mu}-\frac{\partial n_{s 1}}{\partial \mu}=-\frac{\partial n_{c}}{\partial \mu}-\frac{\partial n_{s 1}}{\partial \mu}=\frac{\left(\beta-\bar{q}_{c}\right) z}{D}>(<) 0
$$

the switch to employer-paid parking has an ambiguous effect on $n_{s 2}$, public-transit ridership, as argued above. With both road usage and capacity increasing, the switch also can be shown to have an ambiguous effect on congestion, as measured by the magnitude of $t$.

The changes in $n_{s 1}$ and $n_{c}$ when $k_{1}$ is optimally adjusted are larger than those when $k_{1}$ is held fixed at the first-best level. This conclusion follows because, with $t^{k}+n_{s 1} t^{k n}<0$ assumed to hold, the expression $t+n_{s 1} t^{n}$ falls as $k_{1}$ increases. As a result, compared to the fixed- $k$ 
case, $n_{s 1}$ must increase by more to equate this expression to $\alpha+\gamma_{2}-\beta r_{a}$ when $\mu$ is set at zero. The decline in $n_{c}$ is then also larger, implying a greater suburbanization response to the employer-paid parking switch. A crucial point, though, is that regardless of whether or not $k_{1}$ increases, the shift to road usage completely eliminates the auto commuter's cost savings from employer-paid parking, with costs still equal to the cost of public transit, $\alpha+\gamma_{2}$.

Finally, since the optimality conditions are not satisfied when $\mu=0$, the value of the objective function (consumer utility) is lower with the switch to employer-paid parking. Since both $q_{s}$ and $q_{c}$ are unaffected by the switch, the source of lower utility is a reduction in $e_{s}$ and $e_{c}$. Auto commuting costs (inclusive of suburban parking costs for auto users) are anchored by the cost $\alpha+\gamma_{2}$ of public-transit and are thus unchanged, and central land rent (and thus rental income) is unaffected, so that the decline in the $e$ 's comes from other sources. One source of the $e$ reductions is the lower wage. The residual wage expression $f-\left(1-\beta n_{s 1}-n_{c} q_{c}\right) f^{\prime}$ stays constant with the switch to employer-paid parking, but the residual now must also include subtraction of per-capita (same as total) parking costs, $\beta n_{s 1} f^{\prime}$. The wage is then $f-\left(1-n_{c} q_{c}\right) f^{\prime}$, a smaller value that contributes to the decline in the $e_{i}$ 's and in utility. Note, however, that the road surplus or deficit will also be altered by the switch to employer-paid parking, providing another source of income change through the tax system beyond the effect on the wage. The overall decline in $e_{c}$ and $e_{s}$ from these two sources can be verified from the resource constraint, as seen in the appendix. The decline establishes the harm from switching to employer-paid parking.

Summarizing yields

Proposition 1. Under the assumptions of the model, a switch from the first-best allocation to employer-paid parking leads to an increase in road usage and road capacity. These changes keep auto commuting costs constant at their initial level even though the parking-cost burden has shifted to the employer. The switch leads to greater suburbanization of the city's population and thus a larger commute flow to the center, but there is no change in land consumption, central rent or CBD output, although utility falls due to a reduction in nonland consumption. If capacity is instead held fixed at the first-best level, the increases in road usage and suburbanization are smaller, while the other qualitative effects continue to hold.

Since all these changes disrupt the first-best allocation, the proposition implies that the switch 
to employer-paid parking leads to inefficiently high road usage and capacity investment along with an inefficiently high degree of suburbanization. ${ }^{18}$

The comparative-static analysis so far implicitly assumes that some commuters continue to use public transit as the decline in $\mu$ causes $n_{s 1}$ to rise. Another possibility, however, is that a corner solution is reached before $\mu=0$, with transit use disappearing entirely and all suburban commuters using the road, so that $n_{s 1}=n_{s}$. After replacing $n_{c}$ with $1-n_{s}$, condition (2) then can be written $f^{\prime}\left(1-\beta n_{s}-\left(1-n_{s}\right) \bar{q}_{c}\right)=v^{\prime}\left(\bar{q}_{c}\right)$. This condition determines $n_{s}$, and the capacity condition (5) then determines $k_{1}$, with both values fixed as $\mu$ declines all the way to zero. The only effect of this decline is a continued reduction in the wage as parking costs shift all the way to employers. The upshot is that the conclusions of Proposition 1 continue to hold when the shift to employer-paid parking yields a corner solution for mode choice.

It should be noted that the conclusions in Proposition 1 are closely tied to the assumption of quasi-linear preferences. Without this assumption, however, a numerical approach provides the only route to concrete conclusions, as seen in section 4. Another point to note is that the strict convexity assumption on $n_{s 1} t$ rules out the common ratio form of congestion costs, where $t\left(n_{s 1}, k_{1}\right)=\psi\left(n_{s 1} / k_{1}\right)$. In this case, it can be shown that the Hessian determinant $H$ and thus the determinant $D$ are zero, yielding degenerate derivatives in (11). This outcome reflects the fact that the equation system consisting of (2), (4) and (5) does not have a solution under the ratio form of congestion costs. ${ }^{19}$

\subsection{The effects of a cash-out policy}

As explained in Shoup (1997), a 1992 California law requires large employers offering paid parking to also offer the option of a wage supplement equal to the parking cost, which is available to all workers (drivers plus users of other modes). Shoup's empirical evidence shows that this "cash-out" policy reduces solo driving, with auto commuters shifting to car pools and public transit. Using the current framework, it is easily shown that a cash-out policy restores efficiency, leading to the first-best outcome, as follows.

Starting from a situation with employer-paid parking, adoption of a cash-out policy can be decomposed into two separate steps. First, employer-paid parking is terminated, reducing firms' costs and raising the wage, eliminating the earlier wage loss caused by the policy. Second, 
each employee is given a wage supplement of $\beta f^{\prime}$, the cost of a parking space. However, since this supplement raises costs, the base wage declines by exactly the amount of the supplement, leaving the effective wage unchanged. The upshot is that workers face the same wage as they would in the absence of employer-paid parking while needing to pay their own parking costs, thus leading to the first-best outcome. In actuality, this parking payment is not explicitly made, since workers wanting to park get a space in lieu of the wage supplement. But the outcome is the same as if workers take the supplement and use it to pay for parking. Summarizing yields

Proposition 2. A cash-out policy eliminates the inefficiency of employer-paid parking, leading to the socially optimal outcome.

As will be seen in section 5, this efficiency conclusion is overturned in the presence of taxes.

\subsection{The effects of a change in parking efficiency}

Consider now the effects of an improvement in parking efficiency, which corresponds to a reduction in $\beta$, the land required per parking space. An improvement in parking efficiency could arise from replacement of parking lots with parking structures, which use less land per parking space than surface lots (their capital cost, however, is ignored). Alternatively, a lower $\beta$ could come from a shift in household preferences toward smaller vehicles. For example, a standard parking space size in Los Angeles County is 8.6-by-18 feet, while the space size for a compact car is 7 -by-15 feet. ${ }^{20}$ Mobility through cities with heavy traffic and a shortage of parking may create a need for small vehicles due to their agility, ease of parking and lower fuel consumption, leading to a decline in $\beta$.

The effect on the first-best allocation of a reduction in $\beta$ can be found by setting $\mu=1$ and $d \mu=0$ in (10) and using Cramer's rule to solve for the comparative-static derivatives with respect to $\beta$. Letting $w=-\left(f^{\prime}+r_{a}\right) f^{\prime \prime}>0$ and $y=w n_{s 1} t^{k k}>0$, these derivatives are

$\frac{\partial n_{s 1}}{\partial \beta}=\frac{\bar{q}_{c} y}{D}<0, \quad \frac{\partial n_{c}}{\partial \beta}=-\frac{\beta y+n_{s 1} f^{\prime \prime} H}{D}>(<) 0, \quad \frac{\partial k_{1}}{\partial \beta}=-\frac{\bar{q}_{c} w\left(t^{k}+n_{s 1} t^{k n}\right)}{D}<0$.

Therefore, an improvement in parking efficiency (a reduction in $\beta$ ) naturally raises $n_{s 1}$ and $k_{1}$, while having an ambiguous effect on $n_{c}$. This latter conclusion follows because the change 
in the term $\beta n_{s 1}$ in the argument of $f^{\prime}$ is ambiguous (with one element falling and the other rising), leading to an ambiguous required change in $n_{c}$.

Summarizing yields

Proposition 3. Under the assumptions of the model, an improvement in parking efficiency leads to an increase in road usage and road capacity, no change in land consumption, central rent or CBD output, an increase in utility from an increase in nonland consumption, and ambiguous changes in suburbanization and public-transit ridership.

The utility effect follows from applying the envelope theorem to (1), which shows that the derivative of maximized utility with respect to $\beta$ equals $-\delta n_{s 1} f^{\prime}<0$. While the proposition again applies to an interior mode-choice outcome, if the increase in $\beta$ drives $n_{s 1}$ to zero, so that all commuters use public transit, further $\beta$ increases have no effect.

\section{Numerical Example}

\subsection{The setup}

This section presents a numerical example in order to judge the robustness of the conclusions in section 3 to usage of a different utility function. Rather than assuming quasi-linear preferences, utility is instead assumed to take the Cobb-Douglas form, as shown in Table 1 (the land and nonland exponents are 0.4 and 0.6, respectively). The CBD production function is also assumed to be Cobb-Douglas, so that the intensive form $f(\ell)$ is a power function, with its exponent assumed to equal 0.2 , indicating a realistically low land share in production. The values for the road capacity cost $\left(\gamma_{1}\right)$, the transit user cost $(\alpha)$, the transit capacity $\operatorname{cost}\left(\gamma_{2}\right)$, the parking efficiency parameter $(\beta)$, and agricultural rent $\left(r_{a}\right)$ are also shown in Table 1.

The choice of the transit user-cost function requires additional discussion. A ratio form for this function was inadmissible in the quasi-linear case, as noted above, and a similar issue arises with more-general preferences. In particular, it is easily seen that a ratio form for the $t$ function rules out an interior mode-choice outcome when parking is employer paid, with all commuters using one mode or the other. ${ }^{21}$ To avoid this outcome, which can also arise when the $t$ function has close to a ratio form, the numerical example adopts a $t$ function of the form 
$\tau_{0} n_{s 1}^{\tau_{1}} k_{1}^{-\tau_{2}}$, with $\tau_{1}$ much larger than $\tau_{2}$ (the ratio form would have $\tau_{1}=\tau_{2}$ ). As seen in Table $1, \tau_{1}$ is set at 4.0, with $\tau_{2}$ equal to 1.0. Under these assumptions, which indicate that road capacity investment has a relatively weak effect on congestion, interior mode-choice outcomes occur with both employee-paid and employer-paid parking.

A ratio form of $t$ exhibits homogeneity of degree zero, yielding the well-known self-financing theorem given the maintained assumption of constant road-capacity costs. The $t$ function in Table 1, by contrast, is homogenous of degree 3, which can be shown to imply that toll revenue at the social optimum exceeds the cost of road capacity. As a result, the capacity tax seen in (8) will be negative, indicating a partial rebate of toll revenue.

\subsection{Results}

The numerical results are shown in Table 2, and they reflect the same general pattern of impacts from employer-paid parking seen in section 3. The discussion first focuses on the comparison between the two parking regimes when $k_{1}$ is adjusted optimally, contrasting the first and second columns of numbers. With employee-paid parking, about $80 \%$ of the city's unitary population resides in the suburbs $\left(n_{s}=0.7961\right)$, with an appreciable number of these residents (0.3324) using public transit. Following the switch to employer-paid parking, commuters shift toward road usage, with transit ridership (whose overall change was ambiguous a priori) dropping all the way to 0.0247 and road usage rising from 0.4638 to 0.8251 , a case of low transit usage like that seen in many US cities. These changes lead to a greater overall suburban commute flow, with the suburban population rising to 0.8498 as a result of the switch. In addition, road capacity increases substantially from 0.2072 to 0.8746 , which offsets some of the congestion that would otherwise occur with a surge in road usage. Therefore, the main conclusions of Proposition 1 (an increase in road traffic and capacity accompanied by greater suburbanization) are reaffirmed by the numerical results.

The mode-choice shift from Table 1 is illustrated in Figure 2, which shows how the mode choices vary as a function of $\mu$, the employee's parking cost share from the comparative-static analysis of section 3. The employer-paid and employee-paid parking outcomes in the table correspond to $\mu=0$ and $\mu=1$, but outcomes for intermediate $\mu$ values are shown as well. The "foot" choice in the figure indicates a central residence, which entails the mode choice of 
walking to work.

While land consumption was unaffected by the switch to employer-paid parking under quasi-linear preferences, $q_{c}$ and $q_{s}$ decline slightly in the numerical example. Central parking land rises from 0.0937 to 0.1650 in step with the rise in $n_{s 1}$, but the changes in $q_{c}$ and $n_{c}$ now fail to exactly offset this increase, with production land (which accounts for about $2 / 3$ of central use) falling slightly from 0.6602 to 0.6559 , which reduces output. Given $f^{\prime \prime}<0$, the lower land input raises central land rent from 1.5333 to 1.5414 and thus the cost of an employee parking space, which rises from 0.3067 to 0.3083 . The employee-paid parking cost represents about $8 \%$ of the pre-switch wage of 4.0494 , while after the switch, the higher cost is deducted from the wage, which falls to 3.7358. The road-capacity tax, which is negative as predicted, becomes more negative after the switch, falling from -0.0621 to -0.2624 (from $1.4 \%$ to $6.0 \%$ of the wage plus differential land rent).

Net income for each worker, given by the expression in (8), falls from 4.6449 to 4.5935 after the switch, with the larger toll rebate mostly offsetting the decline in the wage (the rentalincome component, equal to $f^{\prime}-1$, rises slightly). This $1.1 \%$ drop in income translates into reductions in nonland consumption, with $e_{c}$ falling from 2.7869 to 2.7561 and $e_{s}$ falling from 2.3489 to 2.3181 . Reinforced by the declines in $q_{c}$ and $q_{s}$ noted above, the upshot is a decline in utility from 5.2929 to 5.2837 .

Even though resource reallocation is fairly dramatic in response to the switch to employerpaid parking, the net effect on consumer welfare, reflected in the $1.1 \%$ net income loss, is modest. Other major urban distortions, however, produce welfare effects with similar orders of magnitude. For example, Brueckner (2007) shows that imposition of congestion tolls in a realistically calibrated monocentric city produces a welfare gain worth only $0.7 \%$ of income. Borck and Brueckner (2016) find similarly modest welfare gains from imposing optimal emissions taxes in a monocentric city.

As noted in Proposition 1, the mode-choice effects of the switch to employer-paid parking are much less dramatic when $k_{1}$ is held fixed at the first-best level instead of being optimally adjusted, as seen in the third column of Table 2. Rather than dropping to 0.0247, transit ridership only declines to 0.2371 . In addition, the increase in suburbanization is only about 
one-third as large, with $n_{s}$ rising to 0.8127 rather than to 0.8498 . The decline in net income is also smaller. However, since urban road investments in the US have been made conditional on the mode choices spurred by employer-paid parking, the comparison that allows adjustment of $k_{1}$ would appear to be the more relevant one in gauging the effects of this policy. Hence, the proper focus is on the more-dramatic impacts in the second column of Table 2.

As for sensitivity analysis, a main finding is that a reduction in the size of the $n_{s 1}$ exponent in the $t$ function can produce a mode-choice corner solution under employer-paid parking, with all commuters using the road. Other less notable changes occur in response to other parameter changes, while preserving the main features of the outcomes shown in Table 1.

An interesting aspect of the results is that the utility level with employer-paid parking is smaller when $k_{1}$ is adjusted than when it is fixed (5.2837 vs. 5.2932). This relationship may at first appear surprising, but it illustrates the principle that, in the presence of a distortion, satisfaction of the remaining conditions for first-best optimality (namely, the road capacity condition (5)) may not be desirable. In effect, adjustment of $k_{1}$ reinforces the inefficient switch to auto use rather than restraining it. As a result, adjusting $k_{1}$ to satisfy (5) is worse than keeping it fixed when switching to employer-paid parking. However, continued satisfaction of this standard cost-benefit condition would appear to be a realistic description of decisionmaking in response to employer-paid parking, hence the relevance of this case. ${ }^{22}$

\section{The Tax Code and Employer-Paid Parking}

The current US tax law encourages firms to provide fringe benefits that are not taxable for the worker. In the particular case of employer-paid parking, the US IRS Code Section 132(a) encourages employers to convert taxable wages into nontaxable parking subsidies up to a certain limit ( $\$ 255$ per month in 2016$)$. This conversion benefits the worker by reducing his income tax liability while also lowering the tax liability of the employer, whose payroll-tax payment is reduced via the lower wage. As a result, the tax code encourages provision of employer-paid parking, despite its inefficiency.

More formally, let income taxes be added to the model, with $T_{e m p}$ denoting the income-tax rate of the employee (including the payroll tax share) and $T_{\text {firm }}$ denoting the tax rate for the 
firm's share of payroll taxes. The residual giving the wage must now cover the payroll-tax payment as well, so that $f-\ell f^{\prime}=\left(1+T_{f i r m}\right) w$, where $w$ is the wage, which then equals $\left(f-\ell f^{\prime}\right) /\left(1+T_{\text {firm }}\right)$.

With employee-paid parking, the tax payments of the firm and worker are then given by

$$
P_{\text {firm }} \equiv T_{\text {firm }} \frac{f-\ell f^{\prime}}{1+T_{\text {firm }}}, \quad P_{\text {emp }} \equiv T_{e m p}\left(\frac{f-\ell f^{\prime}}{1+T_{\text {firm }}}+f^{\prime}-r_{a}\right)
$$

where the expression multiplying $T_{e m p}$ is the wage plus rental income, with the latter term omitted in $P_{\text {firm }}$. Note that the capacity tax/rebate is excluded from taxable income. With employer-paid parking, the wage residual expression must also include $-\beta f^{\prime} n_{s 1}$, so that the wage falls by $\beta f^{\prime} n_{s 1} /\left(1+T_{f i r m}\right)$. The new tax payments of the employer and worker are then

$$
P_{\text {firm }}-T_{\text {firm }} \frac{\beta f^{\prime} n_{s 1}}{1+T_{\text {firm }}}, \quad P_{\text {emp }}-T_{e m p} \frac{\beta f^{\prime} n_{s 1}}{1+T_{\text {firm }}} .
$$

In the quasi-linear model of section 3 , the $P_{\text {firm }}$ and $P_{e m p}$ terms remain constant in switching to employer-paid parking, so that the tax payments in (14) are smaller than those in (13).

In the previous analysis, auto commuters realistically treat the wage as parametric, not recognizing that the switch to employer-paid parking comes at the cost of a lower wage (which exactly offsets the original gain). In this case, workers would support the switch, viewing employer-paid parking as "free." If workers were instead super-rational, understanding that the wage effect cancels the gain from the switch, they would nevertheless initially prefer the switch because of the tax benefit. Employers would have the same view, encouraging the switch even though transit users enjoy no gain to offset their lower wage. Although utility in the model of section 3 declines via a reduction in nonland consumption following the switch, the present tax reduction works in the opposite direction, appearing to make an increase in utility possible. However, in a closed model with no public goods aside from transportation infrastructure, the income- and payroll-tax revenue must ultimately be returned to workers and firms in a lump-sum fashion. Once this transfer occurs, the tax benefit of employer-paid parking is nullified, so that the original utility loss again obtains. The upshot is that the 
seemingly innocuous tax incentives that can help to spur adoption of employer-paid parking ultimately lead to a welfare reduction, a consequence of the major distortions in mode choice and suburbanization that have been analyzed in this paper.

It is important to note that tax effects undermine the efficiency of a cash-out policy. As explained above, the policy can be viewed as giving all workers a wage supplement equal to the parking cost, which can be returned to the employer in return for a parking space. With income taxation, the wage supplement is taxable, but the tax disappears if the supplement is exchanged for parking. As a result, the additional tax can be viewed as a cost of not using the auto mode (using transit or walking to work in the center). Since this cost will distort mode choice, leading to road usage beyond the first-best level, the cash-out policy does not have the same efficiency benefit as in a world without income taxes. In order to restore policy's efficiency, the fringe benefit of employer-paid parking would need to be taxable, in which case there would be no adverse tax effect from not choosing the auto mode.

\section{Conclusion}

This paper has analyzed the effect of employer-paid parking on aspects of urban form. The analysis shows that, to generate the social optimum, auto commuters should pay their own parking costs while also paying congestion tolls. In switching from this first-best regime of employee-paid parking to one of employer-paid parking, commuters shift from public transit to road usage. While this shift spurs an increase in road capacity, the cost of road usage ultimately rises by enough to eliminate the gain from the absence of parking costs. Since the mode shift from transit to auto use requires more parking land, leaving less for other uses, some central residents relocate to the suburbs. All of these changes are inefficient, leading to a city with too much road usage, too much road investment, and too much suburbanization, effects that reduce the urban utility level. The paper argues that these distortions are encouraged by nontaxability of the fringe benefit of employer-paid parking, which has spurred its adoption.

The analysis shows that, in the absence of income taxes, employer-paid parking's undesirable effects can be reversed by a cash-out policy like the one mandated in California. Such a policy is equivalent to an arrangement where employers give all workers a stipend that can be 
used to cover parking costs or spent elsewhere, effectively restoring the employee-paid parking regime and thus the efficiency of the urban equilibrium. While this conclusion does not hold exactly in the presence of income taxes, the cash-out policy's benefits are partly retained, making it still desirable as remedy for the distortions engendered by employer-paid parking.

Extensions of the model could make the provision of central parking more realistic. One easy extension would replace surface parking with underground parking, which uses no land but entails a high capital cost per parking space. In the model of section 3 , it is easy to see that a switch to employer-paid parking in the underground case leads to familiar inefficient increases in road usage and capacity while having no effect on suburbanization. Following Brueckner and Franco (2016), the case of structural parking could also be analyzed, recognizing that a parking structure of a greater height corresponds to an increase in parking efficiency, but at the cost of greater capital investment, which would be chosen optimally. 


\section{Appendix}

\section{A1. First-order conditions}

The first-order conditions for the planning problem are as follows:

$$
\begin{array}{ll}
u: & 1-\left(\theta_{c}+\theta_{s}\right)=0 \\
e_{c}: & \theta_{c}-\delta n_{c}=0 \\
e_{s}: & \theta_{s}-\delta n_{s}=0 \\
q_{c}: & \theta_{c} v^{\prime}\left(q_{c}\right)-\delta n_{c} f^{\prime}=0 \\
q_{s}: & \theta_{s} v^{\prime}\left(q_{s}\right)-\delta r_{a} n_{s}=0 \\
n_{c}: & -\lambda-\delta\left(q_{c} f^{\prime}+e_{c}\right)=0 \\
n_{s}: & -\lambda-\delta\left(e_{s}+r_{a} q_{s}\right)-\mu=0 \\
n_{s 1}: & -\delta\left(t_{1}+n_{s 1} t^{n}\right)-\phi+\mu=0 \\
n_{s 2}: & -\delta\left(\gamma_{2}+\alpha\right)+\mu=0 \\
k_{1}: & -\delta\left(\gamma_{1}+n_{s 1} t^{k}\right)=0 \\
P: & -\delta\left(\beta f^{\prime}+r_{a} \beta\right)+\phi=0 .
\end{array}
$$

\section{A2. Sign of $\partial e / \partial \mu$}

To maintain equal utilities, $e_{c}$ and $e_{s}$ must change by the same amount as $\mu$ is altered, with the common change denoted by $\partial e / \partial \mu$. Differentiation of the resource constraint with respect to $\mu$, yields, after cancelling terms,

$$
\begin{aligned}
-\frac{\partial e}{\partial \mu} & =\left(t+n_{s 1} t^{n}-\alpha-\gamma_{2}\right) \frac{\partial n_{s 1}}{\partial \mu}-\left(\alpha+\gamma_{2}+e_{s}-e_{c}+r_{a} q_{s}\right) \frac{\partial n_{c}}{\partial \mu} \\
& =\left(-\mu \beta f^{\prime}\right) \bar{q}_{c} z / D+\left(\alpha+\gamma_{2}+e_{s}-e_{c}+r_{a} q_{s}\right) \beta z / D,
\end{aligned}
$$


where (9) is used to substitute for the derivatives of $n_{s 1}$ and $n_{c}$, and where (4) (with $\mu$ appended) is used to substitute for the first term in the first line of (a12). Using (6), (a12) reduces to

$$
\begin{aligned}
-\frac{\partial e}{\partial \mu} & =\left(\alpha+\gamma_{2}+e_{s}-e_{c}+r_{a} q_{s}-\mu f^{\prime} \bar{q}_{c}\right) \beta z / D \\
& =(1-\mu) f^{\prime} \bar{q}_{c} \beta z / D<0 .
\end{aligned}
$$

Thus, $\partial e / \partial \mu>0$ holds, so that a reduction in $\mu$ reduces $e_{c}$ and $e_{s}$. 


\section{Table 1: Functional Forms and Parameter Values}

\begin{tabular}{ll}
\hline \hline Utility function & $\sigma_{0} q^{\sigma_{1}} e^{1-\sigma_{1}}$ \\
$\sigma_{0}$ & 100.0 \\
$\sigma_{1}$ & 0.4 \\
Production function & $\rho_{0} \ell^{\rho_{1}}$ \\
$\rho_{0}$ & 5.5 \\
$\rho_{1}$ & 0.2 \\
Road user cost & $\tau_{0} n_{s 1}^{\tau_{1}} k_{1}^{-\tau_{2}}$ \\
$\tau_{0}$ & 0.2 \\
$\tau_{1}$ & 4.0 \\
$\tau_{2}$ & 1.0 \\
Road capacity cost $\left(\gamma_{1}\right)$ & 0.1 \\
Transit user cost $(\alpha)$ & 0.5 \\
Transit capacity cost $\left(\gamma_{2}\right)$ & 0.23 \\
Parking efficiency $(\beta)$ & 0.2 \\
Agricultural rent $\left(r_{a}\right)$ & 1.0 \\
\hline \hline
\end{tabular}


Table 2: Effects of Employer-Paid Parking

\begin{tabular}{|c|c|c|c|}
\hline & \multicolumn{3}{|c|}{ Parking cost paid by } \\
\hline & \multirow[t]{2}{*}{$\underline{\text { Employee }}(\mu=1)$} & \multicolumn{2}{|c|}{$\underline{\text { Employer }}(\mu=0)$} \\
\hline & & $k_{1}$ adjusted & $k_{1}$ fixed \\
\hline \multicolumn{4}{|l|}{ Variable } \\
\hline Road users $\left(n_{s 1}\right)$ & 0.4638 & 0.8251 & 0.5756 \\
\hline Transit users $\left(n_{s 2}\right)$ & 0.3324 & 0.0247 & 0.2371 \\
\hline Suburban population $\left(n_{s}\right)$ & 0.7961 & 0.8498 & 0.8127 \\
\hline Road capacity $\left(k_{1}\right)$ & 0.2072 & 0.8746 & 0.2072 \\
\hline Central land consumption $\left(q_{c}\right)$ & 1.2117 & 1.1921 & 1.2060 \\
\hline Suburban land consumption $\left(q_{s}\right)$ & 1.5660 & 1.5454 & 1.5600 \\
\hline Parking land $\left(\beta n_{s 1}\right)$ & 0.0928 & 0.1650 & 0.1151 \\
\hline CBD production land $(\ell)$ & 0.6602 & 0.6559 & 0.6590 \\
\hline Central land rent $\left(f^{\prime}\right)$ & 1.5333 & 1.5414 & 1.5356 \\
\hline Central parking cost $\left(\beta f^{\prime}\right)$ & 0.3067 & 0.3083 & 0.3071 \\
\hline $\begin{array}{l}\text { Wage (after subtraction of any emplo } \\
\text { paid parking cost }\end{array}$ & 4.0494 & 3.7898 & 3.8711 \\
\hline Road-capacity tax & -0.0621 & -0.2624 & -0.2234 \\
\hline $\begin{array}{l}\text { Net income (wage }+ \text { diff. rent }- \text { cap } \\
\text { tax })\end{array}$ & 4.6449 & 4.5935 & 4.6301 \\
\hline Central nonland consumption $\left(e_{c}\right)$ & 2.7869 & 2.7561 & 2.7781 \\
\hline Suburban nonland consumption $\left(e_{s}\right)$ & 2.3489 & 2.3181 & 2.3401 \\
\hline Utility & 5.2969 & 5.2837 & 5.2932 \\
\hline
\end{tabular}




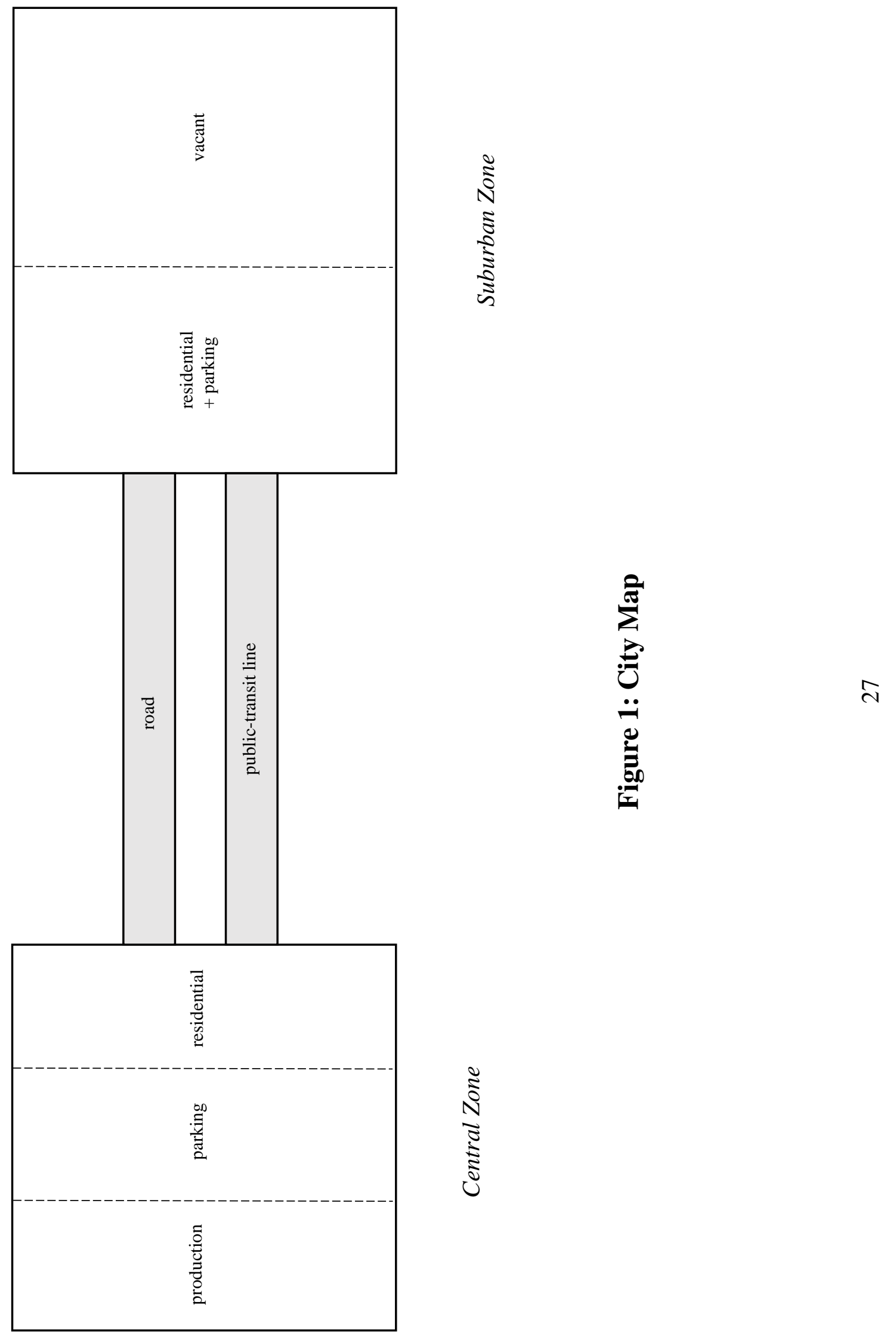


Figure 2: Transportation mode choice for different values of the employee's parking cost share $(\mu)$

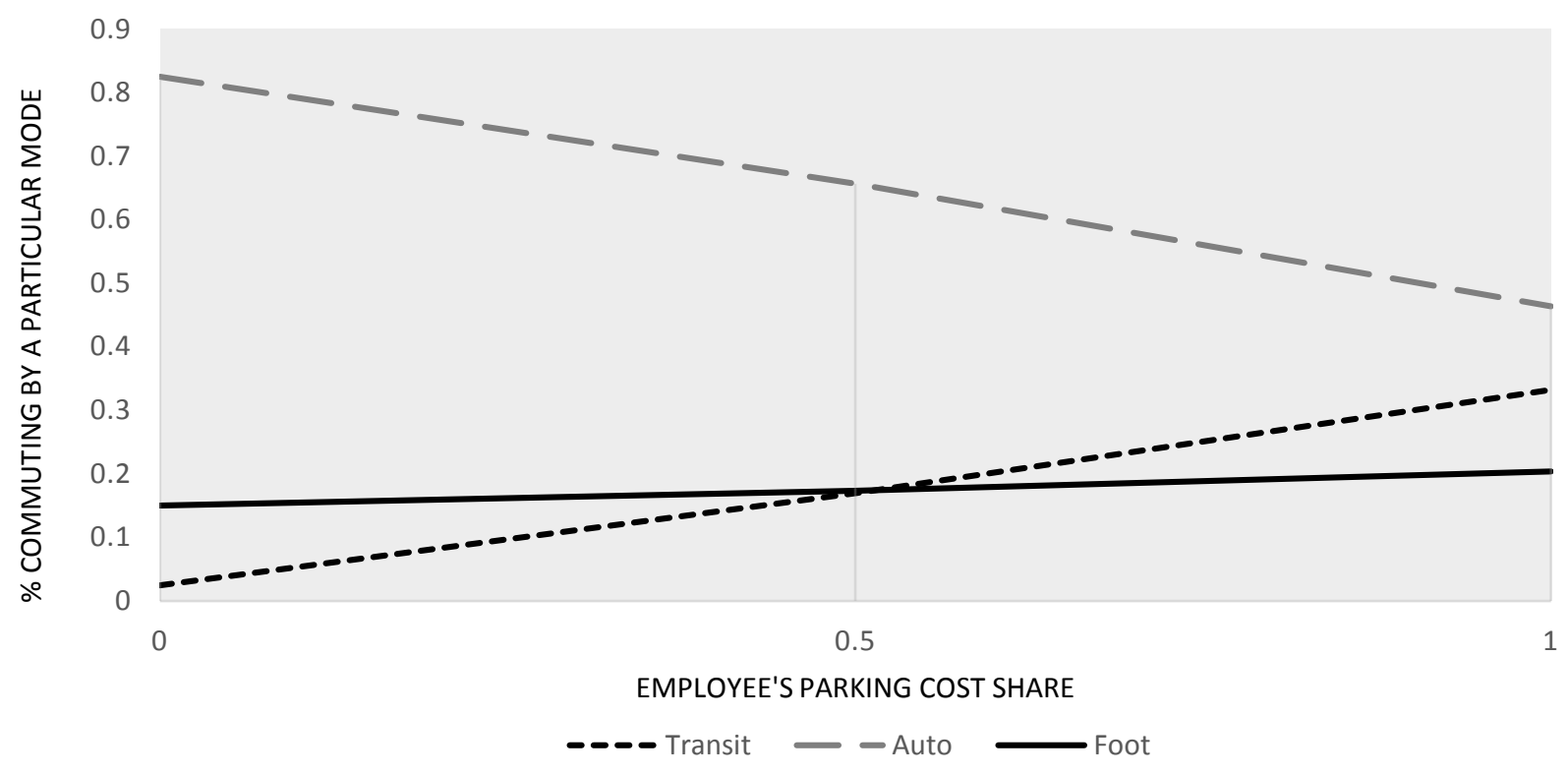




\section{References}

Anderson, S. And A. DE Palma, 2004. The economics of pricing parking. Journal of Urban Economics 55, 1-20.

Arnott, R.J., de Palma, A., Lindsey, R., 1991. A temporal and spatial equilibrium analysis of commuter parking. Journal of Public Economics 45, 301-335.

Arnott, R.J., Rowse, J., 1999. Modeling parking. Journal of Urban Economics 45, 97-124.

Borck, R., Wrede, M., 2005. Political economy of commuting subsidies. Journal of Urban Economics 57, 478-499.

Borck, R., Wrede, M., 2008. Commuting subsidies with two transport modes. Journal of Urban Economics 63, 841-848.

De Borger, B., Wuyts, B., 2009. Commuting, transport tax reform and the labour market: Employer-paid parking and the relative efficiency of revenue recycling instruments. Urban Studies 46, 213-233.

BrueCKNER, J.K., 2007. Urban growth boundaries: An effect second-best remedy for unpriced traffic congestion? Journal of Housing Economics 16, 263-273.

Brueckner, J.K., Franco, S.F., 2016. Parking and urban form. Journal of Economic Geography, in press.

Brueckner, J.K., Helsley, R.W., 2011. Sprawl and blight. Journal of Urban Economics 69, 205-213.

Brueckner, J.K., Borck, R., 2016. Optimal energy taxation in cities. Unpublished paper, UC Irvine.

Calthrop, E., Proost, S., Van Dender, K., 2000. Parking policies and road pricing. Urban Studies 3, 63-76.

ERsoy, F.Y., HAsker, K., InCI, E., 2016. Parking as a loss leader at shopping malls. Transportation Research Part B 91, 98-112.

Franco, S.F., 2014. What are the spatial effects of employer-paid parking at the CBD? Unpublished paper, Nova School of Economics and Business.

InCI, E., 2015. A review of the economics of parking, Economics of Transportation 4, 50-63. 
McKenzie, B., 2015a. Majority of Americans drive to work, but less so for urban millennials. Random Samplings: The Official Blog of the U.S. Census Bureau, August 13. http://blogs . census.gov/2015/08/13/majority-of-americans-drive-to-work-butless-so-for-urban-millennials/

McKenzie, B., 2015b. Who drives to work? Commuting by automobile in the United States. American Community Survey Report, August.https://www. census.gov/hhes/commuting /files/2014/acs-32.pdf

Metropolitan Transportation Authority, 2016. The MTA Network. New York, MTA.

de Palma, A., Lindsey, R., Monchambert, G., 2015. The economics of crowding in public transport. Unpublished paper, University of British Columbia.

Schaller Consulting, 2007. CITYinFLUX, Understanding and Untangling Traffic and Transportation in New York City. http://schallerconsult.com/pub/cityinflux.pdf

Shin, Y.E., Vuchic, V.R, Bruun, E.C., 2009. Land consumption impacts of a transportation system on a city. Transportation Research Record 2110, 69-77.

SHoup, D.C., 1997. Evaluating the effects of cashing out employer-paid parking: Eight case studies. Transport Policy 4, 201-216.

Shoup, D.C., 2005. The High Cost of Free Parking. Chicago, Planners Press.

Shoup, D.C., Breinholt, M.J.. 1997. Employer-paid parking: A nationwide survey of employers parking subsidy policies. In: D.L. Greene, D.W. Jones, and M.A. Delucchi, eds., The Full Costs and Benefits of Transportation: Contributions to Theory, Method .and Measurement. Berlin, Springer.

Society for Human Resource Management, 2013. Employee Benefits: An Overview of Employee Benefits Offerings in the U.S., Alexandria, VA.

Willson R.D., Shoup, D.C., 1990. Parking subsidies and travel choices: Assessing the evidence. Transportation 17, 141-157.

Tirachini, A., Hensher, D.A., Rose, J.M., 2013. Crowding in public transport systems: Effects on users, operation and implications for the estimation of demand. Transportation Research Part A 53, 36-52.

U.S. Environmental Protection Agency, 2005. Parking Cash Out: Implementing Commuter Benefits Under the Commuter Choice Leadership Initiative. National Service Center for Environmental Publications. 
Verhoef, E.T., Nijkamp, P. Rietveld, P., 1995. The economics of regulatory parking policies: The im(possibilities) of parking policies in traffic congestion. Transportation Research Part A 29A, 141-156.

Voith, R., 1998. Parking, transit, and employment in a central business district. Journal of Urban Economics 44, 43-58. 


\section{Footnotes}

*We thank Antonio Russo for an initial discussion that helped launch this research, and we also thank Bruno de Borger for an earlier discussion that pointed to a general absence of research on the optimal land allocation to parking in central cities. For helpful comments on the paper, we are grateful to Rainald Borck and Kangoh Lee.

${ }^{1}$ This value comes from GIS calculations with data provided by the Los Angeles County GIS Data Portal for the boundaries in 2014 of county parking lots 5,000 square feet or larger associated with commercial, industrial and government properties.

${ }^{2}$ See Shin, Vuchic and Bruun (2009).

${ }^{3}$ More recent data from the Society for Human Resource Management (2013) shows $87 \%$ of employers offering free parking.

${ }^{4}$ The 2013 share of solo drives was 77 percent (McKenzie 2015a).

${ }^{5}$ Most theoretical work on the pricing of parking focuses on the efficiency of second-best pricing of parking spots in the absence of congestion tolls (Arnott et al. 1991, Arnott and Rowse 1999, Verhoef et al. 1995, Calthrop et al. 2000, Anderson and de Palma 2004). See Inci (2015) for a survey. Brueckner and Franco (2016) present a spatial analysis of residential as opposed to employee parking, focusing on the choice among different parking technologies (surface, structural and underground) and on the effect of minimum parking requirements. In work more closely related to the present paper, Ersoy, Hasker and Inci (2016) provide an analysis of the interaction of mode choice and provision of parking in the shopping-center context, with some shoppers accessing the mall by car and others by public transit.

${ }^{6}$ See also Borck and Wrede (2005).

${ }^{7}$ While auto users living in the suburbs benefit from the reduction in commuting costs, publictransit riders living near the CBD also benefit because of the subsidy's negative impact on central land rents.

${ }^{8}$ For a comprehensive recent discussion of crowding in public transit, see Tirachini, Hensher and Rose (2013). For an analytical model, see de Palma, Lindsey and Monchambert (2015).

${ }^{9}$ Note that congestion spillovers between the modes are absent. This assumption may be 
unrealistic for bus transit, which shares congested roads with cars.

${ }^{10}$ This pattern is likely in cities with efficient public-transit systems, with households renting or borrowing a car for occasional trips out of the city. For example, New York City is distinguished from other American cities by low private auto ownership and heavy use of public transit. While nearly 86 percent of American workers drive to work, 4 out of every 5 rush-hour commuters to New York City's CBDs avoid traffic congestion by taking transit service (Metropolitan Transportation Authority (2016), McKenzie (2015b)). In cities with less-efficient public-transit systems, both central and suburban households may own a car, but because of congestion, gas prices or even parking costs, households may still decide to commute to work by an alternative less-expensive transportation mode. Such a scenario can be easily accommodated in our framework by assuming that central residents and suburban transit users would also need $\beta P$ worth of land for residential parking. However, none of our qualitative results would change.

${ }^{11}$ The planning problem assumes common consumption levels for suburban residents regardless of their mode choice. Allowing these levels to differ in the problem's setup would introduce additional notation to no effect, since the first-order conditions would imply common consumption levels.

${ }^{12}$ Adding appendix equations (a2) and (a3) and using $n_{c}+n_{s}=1$, it follows that $\delta=1, \theta_{c}=n_{c}$, and $\theta_{s}=n_{s}$. Substituting, (a4) and (a5) reduce to (2) and (3).

${ }^{13}$ Eliminating $\phi$ and $\mu$ in (a8) using (a9) and (a11), the condition reduces to (4).

${ }^{14}$ Combining (a6) and (a7) to eliminate $\lambda$ and substituting for $\mu$ from (a9) yields (6).

${ }^{15}$ Note that if the toll amount were adding to the cost of central parking, there would be no need for explicit congestion tolls.

${ }^{16}$ Convexity is required in the usual road-use optimization problem, where the goal is to maximize consumer benefit (equal to $\int_{0}^{n} D(z) d z$, with $D$ giving demand) minus user costs $n t(n, k)$ and capacity costs $\gamma k$. Convexity of $n t(n, k)$ is required for concavity of this objective function.

${ }^{17}$ Given $t^{k}<0$, a sufficient condition for this outcome is $t^{k n}<0$, which says the effect of a higher $n_{s 1}$ on the individual user cost is smaller the larger is $k$.

${ }^{18}$ In another scenario that may be more realistic, tolls are absent but road capacity is adjusted to satisfy the optimality condition (5). In this case, $n_{s 1} t^{n}$ disappears from (4), leading to 
disappearance of the $t^{n n}$ and $t^{k n}$ terms in the second row of the matrix in (10) (the 2 factor in the first term also becomes 1). These changes make the determinant of the $2 \times 2$ matrix analogous to $M$ ambiguous in sign, implying that none of the comparative-static derivatives analogous to those in (11) can be signed (the determinant equals $n_{s 1} t^{n} t^{k k}-t^{k}\left(t^{k}+n_{s 1} t^{k n}\right)$ ). This ambiguity applies beyond the context of this particular model, arising in any situation where $t(n, k)$ equals a constant $a$ due to the availability of another fixed-cost mode and $-n t^{k}$ equals a constant capacity cost $b$. Comparative statics of this two-equation system with respect to either $a$ or $b$ are ambiguous because the determinant of the system's matrix of derivatives (equal to the above expression, with $n$ replacing $n_{s 1}$ ) has an ambiguous sign.

${ }^{19}$ This conclusion is demonstrated by noting that (5) becomes $\left(n_{s 1} / k_{1}\right)^{2} \tau^{\prime}\left(n_{s 1} / k_{1}\right)=\gamma_{1}$, which determines a solution for $n_{s 1} / k_{1}$. Substituting this solution into (4), the new terms $\tau+$ $\left(n_{s 1} / k_{1}\right) \tau^{\prime}$ are then fixed. But as a result, (2) and (4) require $f^{\prime}$ to equal two different constants, an impossibility.

${ }^{20}$ In some areas, the normal size can be as high as 9-by-19 feet. The size of parking spaces is mandated by local zoning or land-development ordinances and is based on typical use. The lower the turnover, or the more urban the location, the smaller are the spaces that can be tolerated by users. On the other hand, areas with high turnover that are less urban will generally have larger spaces.

${ }^{21}$ Recall from footnote 18 that (5) becomes $\left(n_{s 1} / k_{1}\right)^{2} \psi^{\prime}\left(n_{s 1} / k_{1}\right)=\gamma_{1}$, which determines a solution for $n_{s 1} / k_{1}$. Substituting this solution into (4) with the $\beta f^{\prime}$ term suppressed (being paid the employer), the terms $\psi+\left(n_{s 1} / k_{1}\right) \psi^{\prime}$ are then fixed, making the LHS equal to a constant. If this constant exceeds $\alpha+\gamma_{2}-r_{a}$, all commuters use public transit, with everyone using the road if the inequality is reversed.

${ }^{22}$ This discussion raises the possibility of a second-best optimization problem, where an "employer-paid-parking constraint" would be imposed. However, it is not clear how such a problem would be formulated. 